\title{
Restoration of dopamine release deficits during object recognition memory acquisition attenuates cognitive impairment in a triple transgenic mice model of Alzheimer's disease
}

\author{
Kioko Guzmán-Ramos, ${ }^{1}$ Perla Moreno-Castilla, ${ }^{1}$ Monica Castro-Cruz, ${ }^{1}$ \\ James L. McGaugh, ${ }^{2}$ Hilda Martínez-Coria, ${ }^{2}$ Frank M. LaFerla, ${ }^{2}$ and \\ Federico Bermúdez-Rattoni ${ }^{1,3}$ \\ ${ }^{1}$ Departamento de Neurociencias, Instituto de Fisiología Celular, Universidad Nacional Autónoma de México, 04510 México D.F., \\ Mexico; ${ }^{2}$ Department of Neurobiology and Behavior, Center for the Neurobiology of Learning and Memory, University of California \\ Irvine, Irvine, California 92697-4545, USA
}

\begin{abstract}
Previous findings indicate that the acquisition and consolidation of recognition memory involves dopaminergic activity. Although dopamine deregulation has been observed in Alzheimer's disease (AD) patients, the dysfunction of this neurotransmitter has not been investigated in animal models of AD. The aim of this study was to assess, by in vivo microdialysis, cortical and hippocampal dopamine, norepinephrine, and glutamate release during the acquisition of object recognition memory (ORM) in 5- and 10-mo-old triple-transgenic Alzheimer's disease mice (3xTg-AD) and to relate the extracellular changes to 24-h memory performance. Five- and 10-mo-old wild-type mice and 5-mo-old 3xTg-AD showed significant cortical but not hippocampal dopamine increase during object exploration. On a 24-h ORM test, these three groups displayed significant ORM. In contrast, 10-mo-old 3xTg-AD mice showed impaired dopamine release in the insular cortex during ORM acquisition, as well as significant impairment in ORM. In addition, cortical administration of a dopamine reuptake blocker produced an increase of dopamine levels in the 10-mo-old 3xTg-AD mice and attenuated the memory impairment. These data suggest that activation of the dopaminergic system in the insular cortex is involved in object recognition memory, and that dysfunction of this system contributes to the age-related decline in cognitive functioning of the $3 x \operatorname{Tg}-\mathrm{AD}$ mice.
\end{abstract}

\begin{abstract}
Alzheimer's disease (AD) is an age-related and progressive degenerative disorder generally characterized by two neuropathological features: deposits of amyloid-beta $(\mathrm{A} \beta)$ peptides and neurofibrillary tangles, formed by the hyperphosphorylated microtubulebinding protein tau (Selkoe 2001). These neuropathological features are generally prominent in learning and memory-related brain regions, including the hippocampus, amygdala, and neocortex (Braak and Braak 1991; Nicholson et al. 2010). Because these pathologies are related to synaptic dysfunction leading to neurotransmitter deregulation including acetylcholine deficiency (Davis et al. 1999), several pharmacological therapies for AD focus on the restoration or modulation of cholinergic neurotransmission by acetylcholinesterase inhibitors and muscarinic agonists (Caccamo et al. 2009; Galluzzi et al. 2010). However, there is also evidence that these treatments may increase extracellular levels of dopamine (DA) (Shearman et al. 2006; Preda et al. 2008), suggesting that DA increase may contribute to the therapeutic effect. The possibility that the dopaminergic system may be involved in $\mathrm{AD}$ is suggested by evidence of decreased DA levels assessed in post-mortem brain tissue of AD patients (Winblad et al. 1985; Nazarali and Reynolds 1992; Storga et al. 1996), as well as changes in DA receptor distribution and density in several
\end{abstract}

\footnotetext{
${ }^{3}$ Corresponding author

E-mail fbermude@ifc.unam.mx

Article is online at http://www.learnmem.org/cgi/doi/10.1101/Im.026070.112.
}

brain structures of the temporal lobe (Joyce et al. 1993, 1998; Kemppainen et al. 2003; Kumar and Patel 2007).

Transgenic models of AD are widely used to study the role of $A \beta$ accumulation and tau tangles in the cognitive alterations characteristic of the disease (Chin 2011). The triple transgenic (3xTg-AD) mice develop pathologies associated with AD in a temporal and region-specific manner. After 4 mo of age, 3xTg-AD mice show intraneuronal accumulation of $A \beta$ in the dorsal cortex, although the ventral cortical areas have very scarce $A \beta$ aggregation and no immunohistochemically detectable presence of phospho-tau accumulation, starting to appear at 9 mo of age (Oddo et al. 2003b; Mastrangelo and Bowers 2008). These mice display synaptic and cognitive deficits in several learning tasks starting at 4-6 mo of age (Billings et al. 2005, 2007; Pietropaolo et al. 2008). The synaptic plasticity dysfunctions observed in these mice, such as a defect in long-term potentiation and paired pulse facilitation, appear to be related to the formation of $\mathrm{A} \beta$ oligomers intracellularly (Billings et al. 2005; LaFerla et al. 2007).

Recognition memory is one of the early cognitive impairments observed in both $\mathrm{AD}$ and animal models of AD (Smith and Knight 2002; Viggiano et al. 2008). Several brain structures are involved in the discrimination between novel and familiar stimuli (Zhu et al. 1997; Brown and Aggleton 2001; Bermudez-Rattoni 2004; Barker et al. 2007); among these, the activity of the insular cortex has been related to memory for several types of stimuli, including odor (Bermudez-Rattoni et al. 1988), taste (Bermudez-Rattoni et al. 2004), spatial context (Bermudez-Rattoni et al. 1991), and objects 
(Bermudez-Rattoni et al. 2005; Balderas et al. 2008). Transgenic mice carrying a double mutation of the amyloid precursor protein (APP) have impaired performance in ORM, as well as decreased levels of DA in the hippocampus and prefrontal cortex (Ambree et al. 2009). There is also evidence that DA is involved in ORM formation in normal animals. Pretraining systemic administration, as well as the prefrontal cortex infusions of a D1 receptor blocker impair ORM, whereas post-trial infusion of a D1 agonist enhances long-term ORM (Nagai et al. 2007; de Lima et al. 2011).

Although prior evidence suggests a possible role for DA deregulation in animal models of $\mathrm{AD}$, studies have not investigated the release of DA or other neurotransmitters during learning at different stages of the AD-related pathology formation. The aim of the present study was to assess extracellular release of DA, norepinephrine, and glutamate within the insular cortex (IC) and dorsal hippocampus of 3xTg-AD mice of 5-mo-old (3xTg-AD 5M) and 10-mo-old (3xTg-AD 10M) during ORM acquisition, and to determine the relation of the changes to 24 -h ORM performance. We also analyzed neurotransmitter changes and ORM in age-matched wild-type mice (WT 5M and WT 10M).

\section{Results}

\section{Behavioral performance in object recognition memory}

During the initial exposure to the novel objects, there were no significant differences among groups in the total time spent in the exploration of both objects $\left(F_{(3,20)}=0.514\right.$, NS) (Table 1$)$. As shown in Figure 1A, the recognition index in the acquisition phase indicates that mice had no preference for any object (O1 or $\mathrm{O} 2$ ); two 3xTg-AD mice of 5 mo old and one wild type (WT) of 5 mo old showed an index significantly different from 0.5 during acquisition were removed from further experiments. Twenty-four hours later, mice were tested for discrimination between a familiar object (FO) and a novel one (NO). Five-month-old mice of both genotypes explored the novel object above chance, $\left(t_{(4)}=5.01, P<0.01\right.$ for WT and $t_{(4)}=4.18, P<$ 0.01 for $3 \times \mathrm{Tg}-\mathrm{AD})$. The recognition index of the 10 -mo-old WT mice indicated a clear preference for the novel object similar to the 5 -mo-old WT mice $\left(t_{(5)}=3.05, P<0.01\right.$ vs. 0.5 recognition index). However, the 10-mo-old 3xTg-AD mice were impaired in ORM. On the retention test the novel and familiar objects were explored equally. ANOVA analysis of the ORI revealed no significant differences among groups during the acquisition phase $\left(F_{(3,19)}=\right.$ $0.642, P=0.5975)$. During the test phase, significant differences were found when the novel object exploration was compared among groups $\left(F_{(3,19)}=4.005, P<0.05\right)$; post hoc analysis revealed a significantly lower object recognition index in the $3 \mathrm{xTg}$-AD 10-mo-old group compared with the other behavioral groups $(P<0.05$ vs. WT 5M, $P<0.01$ vs. 3xTg-AD $5 \mathrm{M}$ and $P<$ 0.05 vs. $3 x T g-A D 10 \mathrm{M}$ ) (Fig. 1B). Genotype was confirmed by PCR in all mice.

Table 1. Exploration time during the object recognition memory acquisition and long-term memory test

\begin{tabular}{lcc}
\hline Group & Acquisition $(\mathrm{sec} \pm$ SEM) & Test $(\mathrm{sec} \pm$ SEM) \\
\hline WT 5 mo & $10.20 \pm 1.55$ & $13.44 \pm 2.20$ \\
3xTg-AD 5 mo & $8.02 \pm 3.08$ & $10.74 \pm 4.94$ \\
WT 10 mo & $7.122 \pm 1.90$ & $10.41 \pm 1.80$ \\
3xTg-AD 10 mo & $10.13 \pm 1.63$ & $9.43 \pm 0.67$ \\
\hline
\end{tabular}

The animals explored the arena for 10 min during acquisition, and $24 \mathrm{~h}$ later they explored for $10 \mathrm{~min}$ in the test. Data are depicted as time of exploration in seconds \pm SEM.
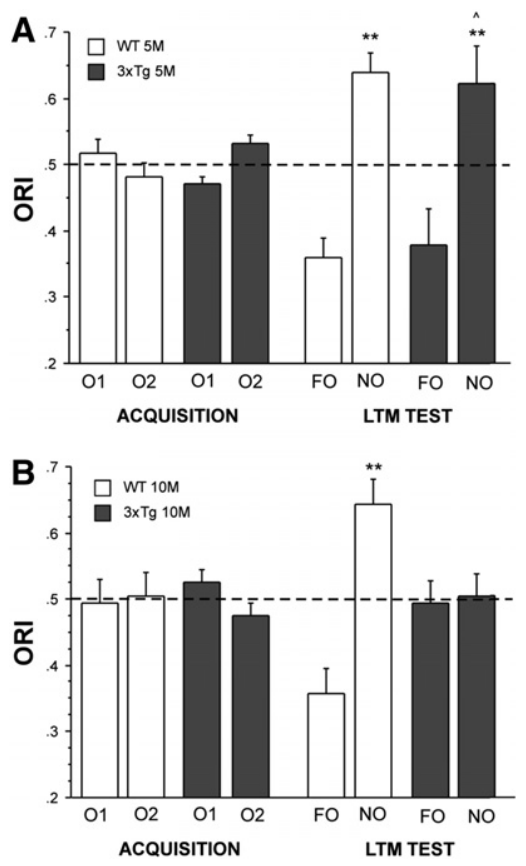

Figure 1. Object recognition index (ORI) during exploration of the objects in the acquisition and long-term-memory test stages. (A) Five-month-old WT (WT 5M, $n=5)$ and $3 \times \operatorname{Tg}-\mathrm{AD}(3 \times \operatorname{Tg} 5 \mathrm{M}, n=5)$ mice explore equally two copies of the same object (O1 and $\mathrm{O} 2$ ) on the acquisition stage; whereas in the long-term memory test (LTM) both groups had a significantly higher ORI of the novel object (NO), preferring it over the familiar object (FO). (B) Ten-month-old WT (WT 10M, $n=6)$ and $3 \times \operatorname{Tg}-\mathrm{AD}(3 \mathrm{x}-\mathrm{Tg} 10 \mathrm{M}, n=7)$ had a similar IRO of both O1 and $\mathrm{O} 2$ during acquisition; however, during the LTM test the $3 \times \mathrm{Tg}-\mathrm{AD}$ failed to discriminate the FO from the NO, indicating an impairment of recognition memory. Data are expressed as ORI = (time spent exploring an object)/(time spent exploring $\mathrm{O} 1+$ time spent exploring $\mathrm{O} 2) \pm$ SEM. (**) $P<0.01$ significantly above chance ( 0.5 value of ORI); $\left({ }^{\wedge}\right) P<$ $0.013 \times T g-A D 5 M$ vs. $3 \times T g-A D 10 M$.

\section{Neurotransmitter changes within the insular cortex and the} hippocampus during the acquisition phase of ORM

Simultaneous microdialysis monitoring of glutamate, dopamine, and norepinephrine enabled comparison of extracellular changes in the sample phase and relate such changes to the animal's behavior. Analysis of the DA concentration in the IC revealed significant differences between the baseline levels of these groups $\left(F_{(3,59)}=\right.$ $23.31, P<0.01)$; a post hoc test revealed that the DA levels were significantly lower in the 3xTg-AD 10M group compared with the WT groups ( $P^{\prime}$ s $<0.01 \mathrm{vs.} \mathrm{WT} \mathrm{5M} \mathrm{and} \mathrm{WT} \mathrm{10M);} \mathrm{the} \mathrm{3xTg-AD} \mathrm{5M} \mathrm{group}$ also had significantly lower levels of dopamine compared with the WT 5M and the WT 10M groups ( $P$ 's $<0.01$ ) (Figs. 2A, 3A). During the presentation of the novel objects, the dopaminergic response was significantly different among genotypes $\left(F_{(1,110)}=18.562\right.$, $P<0.001)$, and a significant genotype $\times$ age interaction was found $\left(F_{(1,110)}=7.704, P<0.01\right)$. When the objects were presented, cortical dopamine increments of about twofold of baseline levels were evident in WT 5M, 3xTg-AD 5M, and WT $10 \mathrm{M}$ mice (WT5M: $F_{(9,80)}=10.706, P<0.01$; 3xTg-AD 5M: $F_{(9,80)}=4.244, P<0.05$; WT10m: $F_{(9,48)}=4.996, P<0.01$ vs. baseline). Interestingly, the 3xTg-AD 10M old did not show a dopamine increase (Fig. 2A).

Baseline concentrations of norepinephrine were significantly different among the analyzed groups $\left(F_{(3,57)}=14.187\right.$, $P<0.01)$; a post hoc test showed that the 3xTg-AD 10M group had significantly lower levels of norepinephrine than the other 

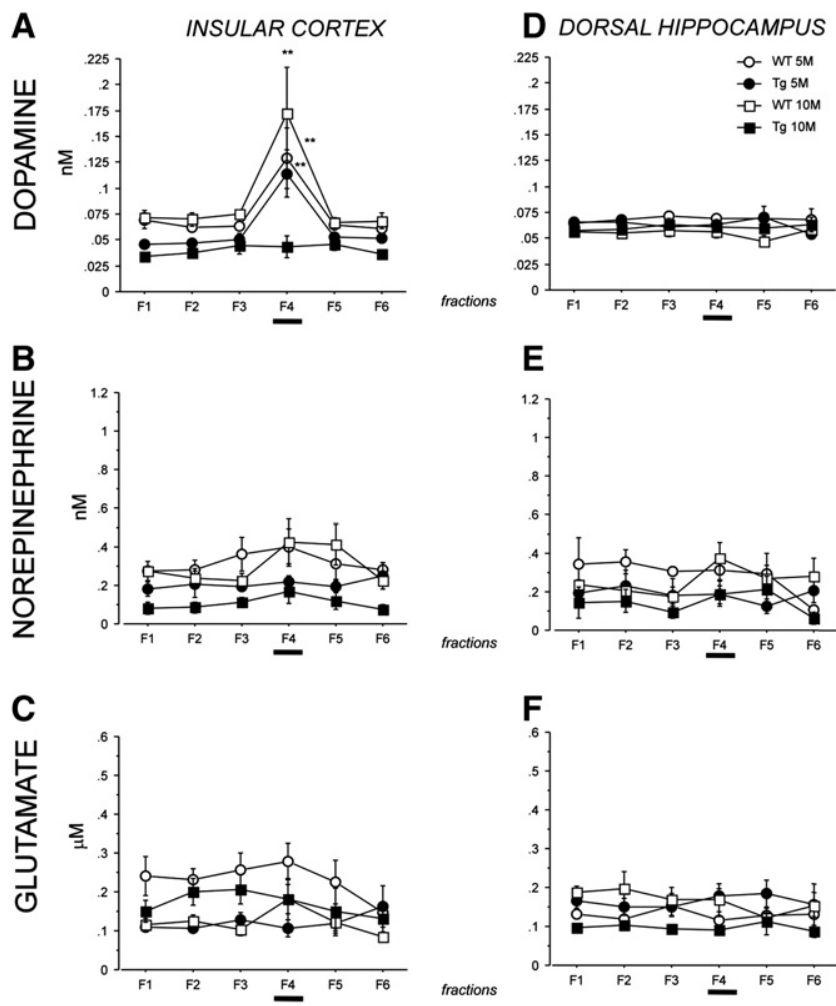

Figure 2. Extracellular changes of dopamine, norepinephrine, and glutamate in the insular cortex and dorsal hippocampus during the initial exploration of two copies of the same object (10 min, black bar) in the acquisition stage of the object recognition memory. $(A)$ Dopamine monitoring in the insular cortex showing a significant increase in the WT mice of 5 and 10 mo old (WT 5M, $n=5$; WT 10M, $n=6$ ) as well as in the 3xTg-AD 5-mo-old mice (Tg 5M, $n=5$ ). Older transgenic mice of 10 mo old ( $\operatorname{Tg} 10 \mathrm{M}, n=7$ ) showed no changes in dopamine release. $(B, C)$ Norepinephrine and glutamate monitoring in the insular cortex indicated no changes related to novel objects exploration. ( $D-F)$ Hippocampal monitoring of dopamine, norepinephrine, and glutamate showed no changes in the acquisition stage. Fractions of $4 \mu \mathrm{L}$ during $16 \mathrm{~min} ; \mathrm{F} 1-\mathrm{F} 3$ are baseline fractions, and F4 represents the effects of objects exploration. Data are expressed as neurotransmitter concentration \pm SEM. $\left({ }^{* *}\right) P<0.01$ vs. the baseline release.

groups ( $\left(P^{\prime} \mathrm{s}<0.01\right)$ (Figs. 2B, 3B). Baseline levels of the 3xTg-AD $5 \mathrm{M}$ group were significantly different from the WT $5 \mathrm{M}$ group $(P<0.01)$, and no significant differences among the WT groups were found. During the novel objects exploration no significant changes from baseline levels were shown (Fig. 2B).

The statistical analysis of the baseline concentrations of glutamate in the IC indicated significant differences between the baseline levels of these groups $\left(F_{(3,58)}=11.194, P<0.01\right)$; a post hoc test revealed that the glutamate levels were significantly higher in the WT $5 \mathrm{M}$ than the other groups ( $P^{\prime} \mathrm{s}<0.01$ ). The 3xTg-AD $10 \mathrm{M}$ group also had significantly higher levels of glutamate compared with the WT $10 \mathrm{M}$ and the $3 \mathrm{xTg}$-AD $5 \mathrm{M}$ groups $\left(P^{\prime} \mathrm{s}<0.01\right)$ (Figs. 2C, 3C). However, no significant changes in the insular cortex were found due to the object exploration in any of the groups studied (Fig. 2C).

Extracellular changes of DA, norepinephrine, and glutamate within the hippocampus were also assessed during ORM acquisition, because this is one of the main brain regions affected by AD pathology. Significant differences were found in the baseline levels of DA $\left(F_{(3,61)}=7.347, P<0.01\right)$. Post hoc tests indicated that the $10 \mathrm{M}$ mice of both genotypes had lower levels of DA than the younger mice ( $\left.P^{\prime} \mathrm{s}<0.01\right)$; however, there were no significant differences on the baseline levels of DA between WT 10M and 3xTg-AD 10M groups (Fig. 2D). The analysis also revealed differences in the baseline levels of norepinephrine among groups $\left(F_{(3,51)}=5.962, P<0.01\right)$. Both $3 x T g-A D 5 \mathrm{M}$ and $3 \times$ Tg-AD $10 \mathrm{M}$ groups and the WT $10 \mathrm{M}$ had significantly lower levels of norepinephrine than the WT 5M ( $\left.P^{\prime} \mathrm{s}<0.05\right)$. No statistical differences were found when objects were presented (Fig. 2E). Glutamate baseline levels in the dorsal hippocampus were different among groups $\left(F_{(3,61)}=8.672, P<0.01\right)$. The $3 \times$ Tg-AD $10 \mathrm{M}$ group had significantly lower levels than the rest of the groups $\left(P^{\prime} \mathrm{s}<0.05\right)$. Interestingly, the WT $10 \mathrm{M}$ mice showed significantly higher levels of glutamate than the WT 5M group $(P<0.05)$. The novel objects exposure did not produce significant extracellular changes of glutamate (Fig. 2F).

\section{Nomifensine retrodialysis administration}

Because the cognitive impairment observed in the 3xTg-AD $10 \mathrm{M}$ mice was associated with a decreased release of cortical dopamine, a subsequent experiment investigated whether extracellular increases of this neurotransmitter would enhance ORM. The DA reuptake blocker, nomifensine (25 $\mu \mathrm{M}$ [Del Arco and Mora 1999], $0.5 \mu \mathrm{L}$ ) was infused into the insular cortex by retrodialysis, and neurotransmitter changes were assessed. Nomifensine administration induced significant changes in dopamine levels $\left(F_{(1,30)}=\right.$ 21.761, $P<0.01)$, and significant differences were found among genotypes $\left(F_{(1,30)}=10.971, P<0.01\right)$; however, there was no significant interaction between the genotype and age of the groups. As shown in Figure 3A, following nomifensine administration, DA increased significantly from baseline levels in all groups to approximately twice their baseline concentration $\left(P^{\prime} \mathrm{s}<0.01\right.$, baseline vs. NOM). Nomifensine administration also affected norepinephrine release among fractions $\left(F_{(1,29)}=6.359, P<0.05\right)$, and among genotypes $\left(F_{(1,29)}=13.595, P<0.01\right)$; no significant interactions were found between genotype and age. Post hoc analysis indicated that NE levels increased significantly from baseline levels in all groups ( $P$ 's $<0.05$ baseline vs. NOM) (Fig. 3B). Nomifensine did not affect glutamate levels (Fig. 3C).

\section{Effect of cortical administration of nomifensine on ORM}

Our results indicate that nomifensine induced a significant increase of DA release in the 10-mo-old 3xTg-AD, in an amount similar to that induced by ORM training (about twofold of baseline release). Hence, we investigated whether the pharmacological increase of DA signaling during ORM acquisition period would enhance the performance of 3xTg-AD 10M mice on short (90 min) and/or long-term $(24 \mathrm{~h})$ memory tests. Mice were habituated to the same chamber as described, and nomifensine was administrated intracortically $20 \mathrm{~min}$ before the novel objects exposure. As shown in Figure 4A, the ORM performance of mice tested 90 min after training was significantly better than that of vehicle controls $(t=2.028, P<0.05)$. ORM was also enhanced on the 24 -h test $(t=2.201, P<0.05)$. The $3 x$ Tg-AD controls showed no object preference, reflecting recognition memory impairment (Fig. 4B).

\section{$A \beta$ accumulation}

To determine the relationship between the behavioral results and the Alzheimer's pathology, we assessed $A \beta$ and tau accumulation in the insular cortex and the dorsal hippocampus of mice in each one of the experimental groups. As it can be seen in Figure 5, there is scarce $A \beta$ deposition in the IC at 5 mo of age, and it is more evident in 3xTg-AD mice of 10 mo old (Fig. 5A,C). The dorsal 
A

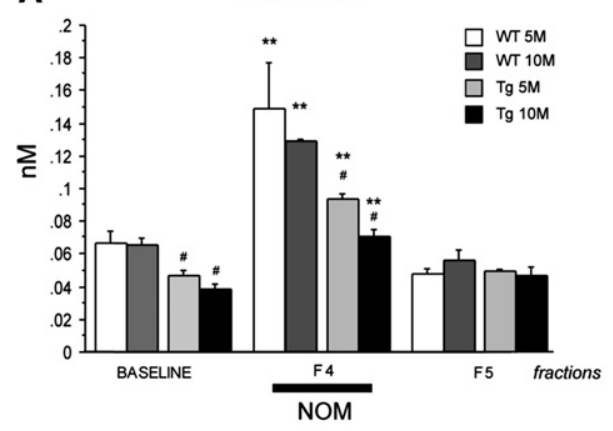

B

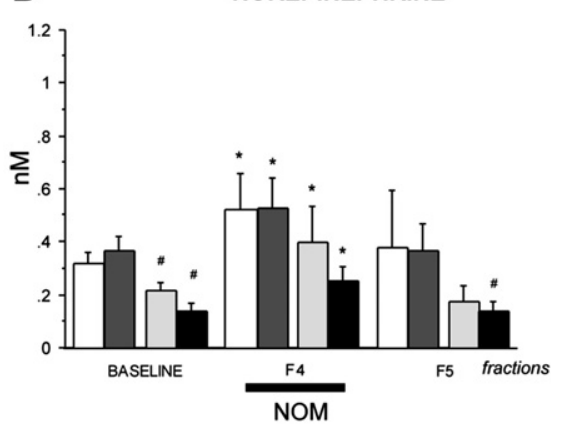

C

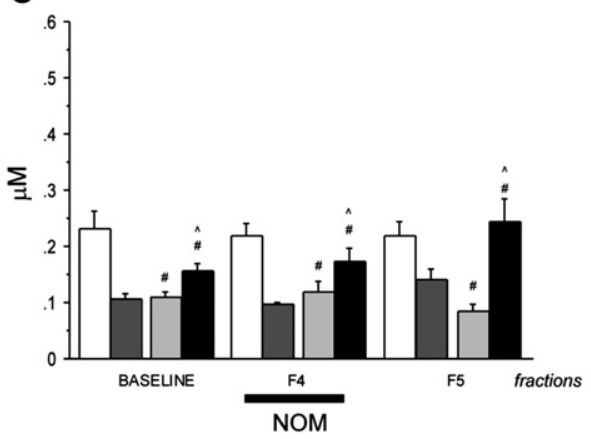

Figure 3. Effects of retrodialysis administration of nomifensine (NOM) on dopamine, norepinephrine, and glutamate extracellular changes within the insular cortex. (A) Dopamine increases with the nomifensine administration ( $25 \mu \mathrm{M}$ ) in all of the mice groups (WT $5 \mathrm{M} n=5, \operatorname{Tg} 5 \mathrm{M} n=5$, WT $10 \mathrm{M}$ $n=4$ and $\operatorname{Tg} 10 \mathrm{M} n=7)$. (B) Norepinephrine shows a significant increase from baseline levels in all mice groups. (C) Glutamate did not show extracellular changes during nomifensine administration. Fractions of $4 \mu \mathrm{L}$ during $16 \mathrm{~min} ; \mathrm{F} 1-\mathrm{F} 3$ values were merged to obtained baseline release, and F4 represents the effects of nomifensine administration. Data are expressed as neurotransmitter concentration \pm SEM. $\left({ }^{*}\right) P<0.01$ vs. baseline fractions; $\left({ }^{\#}\right) P<0.01$ vs. the WT mice of the same age; $\left(^{\wedge}\right) P<0.013 \times T g-A D 10 M$ vs. 3xTg-AD 5M baseline levels.

hippocampus showed more $\mathrm{A} \beta$ accumulation in the 10-mo-old transgenic group compared with the 5-mo-old group of transgenic mice (Fig. 5B,D). The pathological accumulation of tau detected by HT7 immunohistochemistry at these stages of the disease was evident in the dorsal hippocampus, but not in the IC of both 5- and 10-mo 3xTg-AD groups (Fig. 5E-H).

\section{Discussion}

The most widely accepted hypothesis concerning the basis of the cognitive deficits seen in Alzheimer's disease is the accumulation of $A \beta$, which, in turn, is thought to have a main role in tau pathology generation (LaFerla 2010; Querfurth and LaFerla 2010). A major behavioral cognitive impairment in $\mathrm{AD}$ is a deficit in recognizing familiar stimuli, such as faces, objects, places, etc. In the present study, the 3xTg-AD mice displayed an age-related impairment in ORM performance. Such impairment coincided with a lack of dopaminergic response in the IC during the novel objects exploration. The absence of significant extracellular changes in neurotransmitters in the hippocampus is consistent with reports indicating that this structure is not involved in ORM formation when there are no modifications of the spatial context (Rothblat and Kromer 1991; Duva et al. 1997; Stupien et al. 2003; Balderas et al. 2008).

Previous findings indicate that novel stimulation increases DA levels in several brain structures (Feenstra and Botterblom 1996; Ungless 2004; De Leonibus et al. 2006), including the IC (Guzmán-Ramos et al. 2010), a brain structure involved in ORM ac- quisition and consolidation (BermudezRattoni et al. 2005; Balderas et al. 2008). Our present finding that the exposure to novel objects during ORM acquisition increases DA levels in the IC suggests that dopaminergic transmission in the IC is influenced by stimulus novelty. Furthermore, activation of dopaminergic receptors has been proposed as a major contributor to memory formation processes and plastic neuronal changes (Jay 2003; Girault and Greengard 2004; Rossato et al. 2009), including ORM consolidation (Besheer et al. 1999, 2001; de Lima et al. 2011). Previous findings indicate that DA content is decreased in AD brains (Winblad et al. 1985; Nazarali and Reynolds 1992; Storga et al. 1996). Our findings indicate that there is an age-related reduction of cortical DA in 3xTg-AD transgenic mice. There is also evidence that norepinephrine levels are decreased in AD brains (Winblad et al. 1985; Nazarali and Reynolds 1992; Storga et al. 1996). The present findings indicate that basal levels of norepinephrine are lower than those of controls in both the IC and the hippocampus of $3 x T g-A D$ mice. However, we failed to find significant changes in norepinephrine during ORM acquisition. The lack of significant norepinephrine release could be due to the fact that after several days of habituation, ORM is less dependent on norepinephrine activity (Roozendaal et al. 2008). Although, in our case, we habituated the animals for $5 \mathrm{~d}$, making the ORM task relatively stress-free, the role of noradrenergic dysfunction on cognitive impairments in the $3 x T g-A D$ mice remains to be determined specifically.

These findings are, to our knowledge, the first to suggest a dopaminergic deregulation in transgenic mice associated with a cognitive challenge that activates this neurotransmitter system during memory formation. In addition, we found that the replenishment of DA levels by nomifensine administration during the ORM learning attenuated the memory deficit. Initially we verified that local nomifensine administration would lead to the increase of cortical DA levels; the 200\% increment in older 3xTg-AD mice suggests that DA deficits could be due to an impairment of stimulation-induced activation of DA, rather than to the deficit in dopaminergic basal concentrations. Thus, by increasing the extracellular DA with the blockade of re-uptake, we replenished the levels of this neurotransmitter within the IC essential for triggering the molecular events involved in ORM acquisition and consolidation. Other studies using AD-related mice models have reported that cognitive performance is enhanced by increasing dopaminergic activation. Repeated i.p. levodopa injections administered to transgenic mice carrying human APPSwe + Ind (TgCRND8) enhance long-term ORM as well as spatial memory task in a Barnes maze (Ambree et al. 2009). Similarly, systemic administration of the dopamine receptor agonist apomorphine improves water maze performance of 3xTg-AD mice and decreases intraneuronal levels of $A \beta$ in the hippocampus (Himeno et al. 2010). Even though the nomifensine treatment used in the present study was acute and just sufficient to restore DA levels during object exploration, it was probably adequate for enabling the 

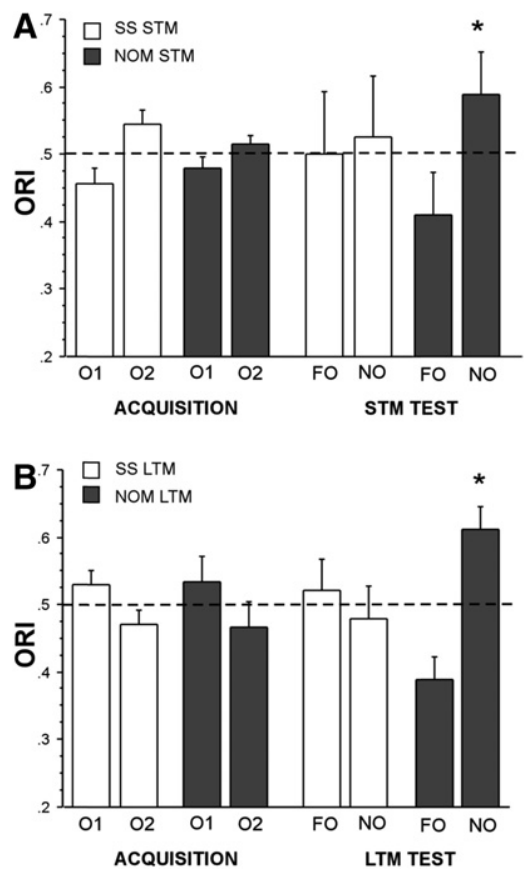

Figure 4. Effect of nomifensine administration in the insular cortex of 3xTg-AD mice of 10 mo old 20 min before the acquisition of object recognition memory. ( $A$ ) Short-term memory (STM) and (B) long-term memory (LTM) tests revealed an enhancement on object discrimination in the transgenic mice that were treated with nomifensine (NOM, $25 \mu \mathrm{M}$, $0.5 \mu \mathrm{L}$ ) compared with groups receiving saline solution (SS). The number of animals per group was SS STM, $n=5$; NOM STM, $n=7$; SS LTM, $n=5$; NOM LTM, $n=6$. (O1) Object 1 ; (O2) object 2; (FO) familiar object; (NO) novel object. Data are represented as ORI \pm SEM. $\left(^{*}\right) P<$ 0.05 vs. familiar object in the same group and vs. 0.5 hypothetic ORI.

initiation of the molecular mechanisms to form ORM. At the present time, the question of whether the stability of such memory is similar to that of the WT or young 3xTg-Ad mice remains to be determined.

The specificity of the DA dysfunction during the acquisition of this task could be explained through the altered membrane permeability to calcium and cellular damage produced by A $\beta$ and tau aggregation causing synaptic dysfunction in the 3xTg-AD mice. Accordingly, it was recently found that activation of D1 receptors with a selective agonist in hippocampal slices protects synapses from deleterious effects on LTP and prevents the decrease of surface NMDA and AMPA receptors caused by A $\beta$ exogenous administration in hippocampal neurons (Jurgensen et al. 2010). Another possible basis of the DA dysfunction during the acquisition stage is related to the influence of cholinergic transmission over neurotransmitters release, including DA. Acetylcholine dysfunction, which has been widely reported in the AD pathology, leads to altered cholinergic stimulation of nicotinic acetylcholine receptors, which modulates DA release in cortical projections (Sarter et al. 2007; Martorana et al. 2009). Infusion of $A \beta$ 1-40 impairs the DA release evoked by the administration of cholinergic agonists (carbachol and nicotine) by retrodialysis in the nucleus accumbens (Preda et al. 2008). Accordingly, cholinergic and dopaminergic dysfunctions in $\mathrm{AD}$ are likely to occur together due to a cholinergic control of DA release.

Among the multiple causes of the pathology observed in the 3xTg-AD mice, dopaminergic system dysfunction may be a target of consideration. In this regard, it has been reported that mice carrying a double mutated form of the human APP, which rapidly develops amyloid plaques at 3 mo of age, have a decrease in DA content in the prefrontal cortex, hippocampus, and neostriatum. The cognitive deficits related with this mice model can be ameliorated by systemic and repeated administration of L-DOPA (Ambree et al. 2009). It has also been reported that, as we have seen in this study, novel stimulation induces significant DA release (Girault and Greengard 2004; Ungless 2004; De Leonibus et al. 2006; Schultz 2007; Guzmán-Ramos et al. 2010). Therefore, it might be that increased exposure to novel stimuli is beneficial in influencing the cognitive performance of transgenic $\mathrm{AD}$ mice models (Jankowsky et al. 2005; Cracchiolo et al. 2007). Therapies involving environment enrichment and cognitive challenges engaging the dopaminergic system may aid in protecting neurons from $\mathrm{A} \beta$ accumulation in the $3 \mathrm{xTg}-\mathrm{AD}$ as they begin to express neuronal pathology.

\section{Materials and Methods}

\section{Animals}

Homozygous 3xTg-AD and non-transgenic (WT) male mice were used. Animals of two ages were analyzed, 5 and 10 mo old of both genotypes. The transgenic mice have been characterized elsewhere (Oddo et al. 2003a,b). Briefly, human APP cDNA harboring the Swedish mutation (KM670/671NL) and human four-repeat tau harboring the P301L mutation were comicroinjected into
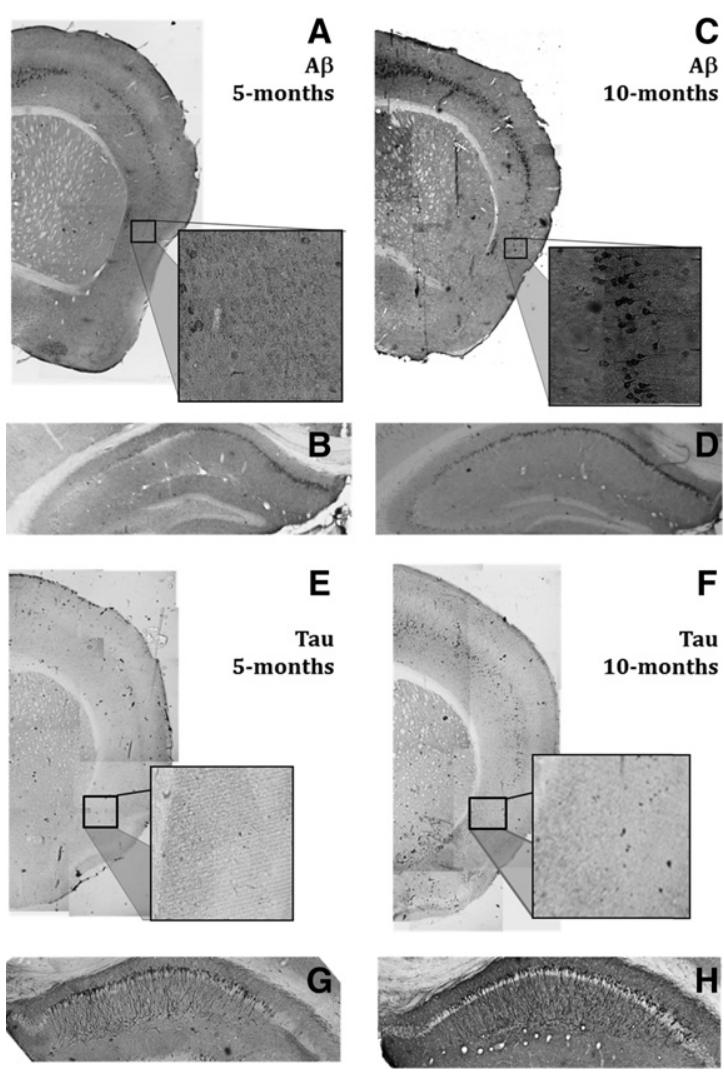

Figure 5. Amyloid $\beta$ deposition in the insular cortex and dorsal hippocampus. $(A, B)$ Coronal sections of $3 \times$ Tg-AD 10-mo brain showing deposition of $A \beta$ and tau, respectively. Note the absence of $A \beta$ at 5 mo in the IC and a clear disposition in the hippocampus. (C,D) Coronal sections showing a clear cortical and hippocampus deposition of $A \beta$ and tau, respectively, in $3 \times \mathrm{Tg}$-AD mice of $10 \mathrm{mo}$. $(E, F)$ Coronal sections of 3xTg-AD 5-mo brain showing deposition of $A \beta$ and tau, respectively. $(G, H)$ Coronal sections showing hippocampus deposition of $A \beta$ and tau, respectively, in $3 \times T g-A D$ mice of 5 mo. 
single-cell embryos of homozygous PS1M146V knock-in mice. The background of the PS1 knock-in mice is a hybrid 129/ C57BL/6. WT mice were from the same strain and genetic background as the PS1 knock-in mice, but they harbor the endogenous wild-type mouse PS1 gene. The experiments were performed in accordance with the Norma Oficial Mexicana (NOM-062-ZOO-1999) and with the approval of the local animal care committee.

\section{Genotyping}

We used the HOT SHOT method (Rudbeck and Dissing 1998) for DNA extraction. It consists of lysis of $\sim 1 \mathrm{~mm}$ of tail snip in an alkaline reagent ( $\mathrm{NaOH} 25 \mathrm{mM}, 0.2 \mathrm{mM}$ disodium EDTA) with heat $\left(95^{\circ} \mathrm{C}, 1 \mathrm{~h}\right)$ and neutralization with a suitable buffer $(1 \mathrm{M}$ Tris- $\mathrm{HCl}$ at $\mathrm{pH}$ 7.5). This DNA, although impure, is suitable for PCR amplification (QIAGEN kit). The primers used for APP-tau PCR were 5tauRev (5'-TCCAAAGTTCACCTGATAGT-3'), APPinternal (5'-G CTTGCACCAGTTCTGGATGG-3'), and Thy12.4 (5'-GAGGTATT CAGTCATGTGCT-3'); for PS1 amplification, we used PS1-K13 (5'-CACACGCACACTCTGACATGCACAGGC-3') and PS1-K15 (5'-AGGCAGGAAGATCACGTGTTCCAAGTAC-3').

\section{Surgical procedure}

Mice were mounted on a stereotaxic apparatus with a mice adaptor and maintained under anesthesia with isoflurane (1.25\%-2.0\%). To avoid eye damage, a thin layer of optical lubricant was applied during the surgery. A small section of scalp was cut, and bregma was adjusted to the horizontal plane with $\lambda$. Two microdialysis guide cannulae (CMA/7; CMA Microdialysis) were implanted aiming to the insular cortex (DV $-2.75 \mathrm{~mm}$; $\mathrm{AP}+1.1 \mathrm{~mm}$; $\mathrm{L}$ $-3.3 \mathrm{~mm}$ ) and to the hippocampus (DV $-1.25 \mathrm{~mm}$; AP $-1.5 \mathrm{~mm}$; L $+2.3 \mathrm{~mm}$ ) (Paxinos and Franklin 2007) and secured with small screws and dental cement. For the drug administration experiment, bilateral 23-gauge stainless steel cannulae $(9 \mathrm{~mm}$ long; Small Parts) were implanted aiming to the insular cortex (DV $-2.75 \mathrm{~mm}$; AP $+1.1 \mathrm{~mm}$; $\mathrm{L}-3.3 \mathrm{~mm}$ ). Dummy cannulae (33-gauge, $12 \mathrm{~mm}$ ) were inserted into the guide cannulae to prevent clogging. Local antibiotics were applied (polymixyn B and iodine) in the wound. Following surgery recovery, all mice were individually housed in plastic cages at a room temperature of $22^{\circ} \mathrm{C}-24^{\circ} \mathrm{C}$ and a $12 / 12$ light/dark schedule with water and food ad libitum.

\section{Behavioral training}

All mice were allowed to recover from surgery for $7 \mathrm{~d}$ before handling. Habituation was carried out on a microdialysis chamber (Bioanalytical Systems, Inc.) with a round black plastic area of $25 \mathrm{~cm}$ diameter $\times 15 \mathrm{~cm}$ high on the interior; this way the animals could explore the entire perimeter and the objects without tapping the microdialysis tubing on the objects on the monitoring day. During a period of $10 \mathrm{~min}$ for $5 \mathrm{~d}$, mice were placed on the chamber with a small ribbon belt around the neck to hold a wire attached to the swivel mechanisms of the microdialysis chamber to prevent the tubing from tangling during the exploration. The chamber and objects were wiped down with $70 \%$ ethanol, and the sawdust was replaced before the placement of each animal. The day of the initial exposure mice were placed on the chamber, and two identical objects were introduced and fixed firmly to the base with Velcro tape $5 \mathrm{~cm}$ from the wall. The objects to explore were red plastic cubes $\left(3.3 \mathrm{~cm}^{3}\right)$ or small amber glass vials with a black lid $(1 \mathrm{~cm}$ diameter $\times 1.8 \mathrm{~cm}$ height $)$. Video recording was made during the exploration period $(10 \mathrm{~min})$ and during the test period $(10 \mathrm{~min}) 24 \mathrm{~h}$ later. On the memory test, mice were placed in the chamber, and a copy of the familiar object and a new object were presented. The object recognition index was calculated as the rate of the (exploration time of novel or familiar object)/(exploration time of novel + familiar object). A recognition index equal to 0.5 reflects no preference in exploration of any object, whereas an index $>0.5$ indicates a preference in exploration.

\section{Microdialysis procedure}

On the monitoring day, a dialysis probe with a $1-\mathrm{mm}$ membrane (CMA 7 MD Probe; CMA Microdialysis) was connected to the microinfusion pump system (CMA Microdialysis), which infused artificial cerebrospinal fluid (ACSF, $125 \mathrm{mM} \mathrm{NaCl}, 5 \mathrm{mM} \mathrm{KCl}$, $1.25 \mathrm{mM} \mathrm{NaH}_{2} \mathrm{PO}_{4} \mathrm{H}_{2} \mathrm{O}, 1.5 \mathrm{mM} \mathrm{MgSO}{ }_{4} 7 \mathrm{H}_{2} \mathrm{O}, 26 \mathrm{mM} \mathrm{NaHCO}_{3}$, $2.5 \mathrm{mM} \mathrm{CaCl}_{2}, 10 \mathrm{mM}$ glucose) at a rate of $1.0 \mu \mathrm{L} / \mathrm{min}$. The length of the outflow connection tubing was measured to calculate the "dead volume" (inner volume of the tubing $\times$ length of the tubing $\times$ infusion rate), which causes a delay between the beginning of the behavioral response and the correspondent microdialysis fraction. After insertion of the probe, $1 \mathrm{~h}$ of fluid stabilization was allowed; samples were collected at a rate of $0.25 \mu \mathrm{L} / \mathrm{min}$ every $16 \mathrm{~min}$ in vials containing $1 \mu \mathrm{L}$ of antioxidant mixture $(0.25 \mathrm{mM}$ ascorbic acid, $0.27 \mathrm{mM} \mathrm{Na}_{2}$ EDTA, $0.1 \mathrm{M}$ acetic acid) and immediately frozen at $-80^{\circ} \mathrm{C}$. Three fractions were collected as baseline samples before the stimulus exposure began (objects exploration) and two more fractions were collected.

Since it has been reported that synaptic dysfunction starts in this model from 6 to 7 mo of age, we analyzed a group of triple transgenic mice of 5 mo that do not show cognitive impairment (Oddo et al. 2003b) (3xTg-AD 5M, $n=5$ ) and compared this group with wild-type mice of the same age (WT $5 \mathrm{M}, n=5$ ). To evaluate the changes in neurotransmission and their relation with the cognitive impairment that develops through aging, we monitored 3xTg-AD 10-mo-old mice (3xTg-AD 10M, $n=7$ ) and compared their performance and extracellular changes with those of wildtype animals of the same age (WT $10 \mathrm{M}, n=6$ ).

\section{Retrodialysis procedure}

Drugs delivered by retrodialysis were perfused through the membrane probe that is inserted in the brain structure of interest; in this case, a syringes changing mechanism (CMA Microdialysis) was used to switch from a syringe containing ACSF to the one containing nomifensine $(25 \mu \mathrm{M})$ that was perfused during the fourth fraction $(0.5 \mu \mathrm{L}$ at a rate of $0.25 \mu \mathrm{L} / \mathrm{min}$, infused for $2 \mathrm{~min})$, and the ACSF perfusion was switched back to continue sample collection.

\section{Analysis of glutamate and dopamine in microdialysis samples}

The neurotransmitter concentrations were determined by capillary electrophoresis as described previously (Guzmán-Ramos et al. 2010). Briefly, the procedure for microdialysis sample analysis was derivatization with $6 \mu \mathrm{L}$ of $16.67 \mathrm{M} 3$-(2-furoyl) quinoline2 -carboxaldehyde (FQ, Molecular Probes, Invitrogen) in the presence of $2 \mu \mathrm{L}$ of $25 \mathrm{mM} \mathrm{KCN}$ in $10 \mathrm{mM}$ borate buffer ( $\mathrm{pH} 9.2)$ and $1 \mu \mathrm{L}$ of internal standard $(0.075 \mathrm{mM}$ O-methyl-L-threonine; Sigma-Aldrich). The mixture was allowed to react in the dark for $15 \mathrm{~min}$ at $65^{\circ} \mathrm{C}$. Separation and analysis were conducted in a Capillary Electrophoresis system (Beckman-Coulter PACE/MDQ, Glycoprotein System) with laser-induced fluorescence detection; light at $488 \mathrm{~nm}$ from an argon ion laser was used to excite the FQ-labeled analytes. The separation of compounds was based on a micellar electrokinetic chromatography method, the buffer composition was $35 \mathrm{mM}$ borates, $25 \mathrm{mM}$ sodium dodecylsulfate, and $13 \%(\mathrm{v} / \mathrm{v})$ methanol HPLC grade, final $\mathrm{pH}$ 9.6. The samples were injected hydrodynamically at $0.5 \mathrm{psi}$ for $5 \mathrm{sec}$ in a $75 \mu \mathrm{m}$ i.d. capillary (Beckman Coulter); then the separation was performed at $25 \mathrm{kV}$. After each sample run, the capillary was flushed with $0.1 \mathrm{M} \mathrm{NaOH}$, water, and running buffer. The neurotransmitters peaks were identified by matching the migration pattern of the electropherogram with an electropherogram resulting from a spiked sample (i.e., addition of derivatized standards of dopamine, norepinephrine, and glutamate). The peak areas were corrected by relating the area under the curve of the corresponding peak with the area under the curve of the internal standard. Data were analyzed using Karat System Gold (Beckman Coulter) generating a calibration curve of six points. 


\section{Drug administration}

Nomifensine (25 $\mu \mathrm{M}$ in ACSF; Sigma-Aldrich) or ACSF administration was made through 30-gauge dental needles that protruded $1 \mathrm{~mm}$ from the tip of the guide cannulae. Injection needles were connected via polyethylene tubing to two 10- $\mu$ L Hamilton syringes, driven by an automated micro infusion pump (Carnegie Medicine). A total volume of $0.5 \mu \mathrm{L}$ per hemisphere was delivered at a rate of $0.25 \mu \mathrm{L} / \mathrm{min} 15 \mathrm{~min}$ before the objects exposure. After microinfusions were completed, the injection needles were left in the guide cannulae for an additional minute to allow diffusion of the solutions into the tissue. A short-term memory test was conducted after $90 \mathrm{~min}$ of the acquisition phase in both nomifensine (NOM STM, $n=7$ ) and ACSF (ACSF, $n=5$ ) groups. Separated groups were tested $72 \mathrm{~h}$ after the acquisition to evaluate long-term memory (NOM LTM, $n=6$ and ACSF, $n=5$ ).

\section{Immunohistochemistry}

After the behavioral experiments, mice were sacrificed with the administration of a lethal dose of pentobarbital $(>50 \mathrm{mg} / \mathrm{kg}$ i.p.) and perfused intracardially with saline solution $(0.9 \%, \mathrm{w} / \mathrm{v})$ at $37^{\circ} \mathrm{C}$ and cold fixation buffer $(0.4 \%$ folmaldehyde and $1 \%$ glutaraldehyde in $0.2 \mathrm{M}$ phosphate buffer at $\mathrm{pH}$ 7.4). The brain was extracted and stored in fixation buffer for $24 \mathrm{~h}$; afterward sucrose gradients $(10 \%, 20 \%$, and $30 \%$ in phosphate buffer) were used as cryoprotection. Sections of $40 \mathrm{~mm}$ were collected from the lesion area left by the cannulae insertion; some sections were processed for free-floating immunohistochemistry described elsewhere (Oddo et al. 2003b, 2004). The anti-A $\beta$ antibody (6E10 Signet; 1:1000) or anti-tau HT7 antibody (Sigma-Aldrich; 1:2000) were applied overnight at $4^{\circ} \mathrm{C}$ and developed with diaminobenzidine (DAB; Vector Labs) using the avidin horseradish peroxidase system (Vector Labs). The remaining sections were stained with cresyl violet and examined by light microscopy in order to verify cannulae placement. All animals included in the analysis had the probe placement within the insular cortex or the hippocampus (see Fig. 6).

\section{Statistical analysis}

Object recognition indexes were analyzed using a two-way ANOVA (genotype $\times$ age). Fisher post hoc tests were used to indicate significant differences between groups. One group Student's $t$-tests with hipothetic media at 0.5 were used to determine object exploration preference above chance. The probability level of $P<$ 0.05 was accepted as statistical significance. Statistical analysis of extracellular changes in the dialysates was performed using multifactor ANOVA (novel stimulus presentation or nomifensine administration $\times$ age $\times$ genotype) with a Fisher post hoc test. A value of $P<0.05$ was considered statistically significant.

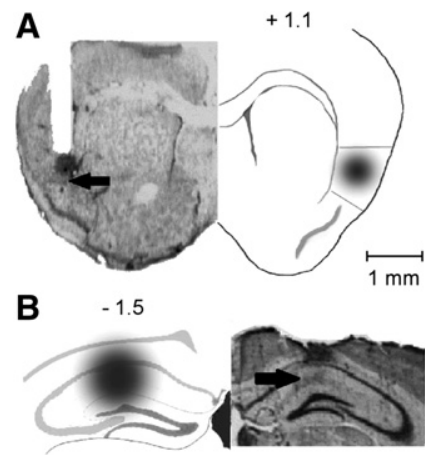

Figure 6. Photomicrographs indicating the cannulae tips (arrows) in the insular cortex $(A)$ and the dorsal hippocampus $(B)$.

\section{Acknowledgments}

We thank Oreste Carbajal for the technical support. This work was supported by CONACYT 0155242, UC-Mexus 2007, and the Miguel Alemán Foundation.

\section{References}

Ambree O, Richter H, Sachser N, Lewejohann L, Dere E, de Souza Silva MA, Herring A, Keyvani K, Paulus W, Schabitz WR. 2009. Levodopa ameliorates learning and memory deficits in a murine model of Alzheimer's disease. Neurobiol Aging 30: 1192-1204.

Balderas I, Rodriguez-Ortiz CJ, Salgado-Tonda P, Chavez-Hurtado J, McGaugh JL, Bermudez-Rattoni F. 2008. The consolidation of object and context recognition memory involve different regions of the temporal lobe. Learn Mem 15: 618-624.

Barker GR, Bird F, Alexander V, Warburton EC. 2007. Recognition memory for objects, place, and temporal order: A disconnection analysis of the role of the medial prefrontal cortex and perirhinal cortex. J Neurosci 27: $2948-2957$.

Bermudez-Rattoni F. 2004. Molecular mechanisms of taste-recognition memory. Nat Rev Neurosci 5: 209-217.

Bermudez-Rattoni F, Forthman DL, Sanchez MA, Perez JL, Garcia J. 1988. Odor and taste aversions conditioned in anesthetized rats. Behav Neurosci 102: 726-732.

Bermudez-Rattoni F, Introini-Collison IB, McGaugh JL. 1991. Reversible inactivation of the insular cortex by tetrodotoxin produces retrograde and anterograde amnesia for inhibitory avoidance and spatial learning. Proc Natl Acad Sci 88: 5379-5382.

Bermudez-Rattoni F, Ramirez-Lugo L, Gutierrez R, Miranda MI. 2004. Molecular signals into the insular cortex and amygdala during aversive gustatory memory formation. Cell Mol Neurobiol 24: 25-36.

Bermudez-Rattoni F, Okuda S, Roozendaal B, McGaugh JL. 2005. Insular cortex is involved in consolidation of object recognition memory. Learn Mem 12: 447-449.

Besheer J, Jensen HC, Bevins RA. 1999. Dopamine antagonism in a novel-object recognition and a novel-object place conditioning preparation with rats. Behav Brain Res 103: 35-44.

Besheer J, Short KR, Bevins RA. 2001. Dopaminergic and cholinergic antagonism in a novel-object detection task with rats. Behav Brain Res 126: $211-217$.

Billings LM, Oddo S, Green KN, McGaugh JL, LaFerla FM. 2005. Intraneuronal $\mathrm{A} \beta$ causes the onset of early Alzheimer's disease-related cognitive deficits in transgenic mice. Neuron 45: 675-688.

Billings LM, Green KN, McGaugh JL, LaFerla FM. 2007. Learning decreases $\mathrm{A} \beta * 56$ and tau pathology and ameliorates behavioral decline in 3xTg-AD mice. J Neurosci 27: 751-761.

Braak H, Braak E. 1991. Neuropathological stageing of Alzheimer-related changes. Acta Neuropathol 82: 239-259.

Brown MW, Aggleton JP. 2001. Recognition memory: What are the roles of the perirhinal cortex and hippocampus? Nat Rev Neurosci 2: 51-61.

Caccamo A, Fisher A, LaFerla FM. 2009. M1 agonists as a potential disease-modifying therapy for Alzheimer's disease. Curr Alzheimer Res 6: 112-117.

Chin J. 2011. Selecting a mouse model of Alzheimer's disease. Methods Mol Biol 670: 169-189.

Cracchiolo JR, Mori T, Nazian SJ, Tan J, Potter H, Arendash GW. 2007. Enhanced cognitive activity-over and above social or physical activity-is required to protect Alzheimer's mice against cognitive impairment, reduce $A \beta$ deposition, and increase synaptic immunoreactivity. Neurobiol Learn Mem 88: 277-294.

Davis KL, Mohs RC, Marin D, Purohit DP, Perl DP, Lantz M, Austin G, Haroutunian V. 1999. Cholinergic markers in elderly patients with early signs of Alzheimer disease. JAMA 281: 1401-1406.

Del Arco A, Mora F. 1999. Effects of endogenous glutamate on extracellular concentrations of GABA, dopamine, and dopamine metabolites in the prefrontal cortex of the freely moving rat: Involvement of NMDA and AMPA/KA receptors. Neurochem Res 24: 1027-1035.

De Leonibus E, Verheij MM, Mele A, Cools A. 2006. Distinct kinds of novelty processing differentially increase extracellular dopamine in different brain regions. Eur J Neurosci 23: 1332-1340.

de Lima MN, Presti-Torres J, Dornelles A, Siciliani Scalco F, Roesler R, Garcia VA, Schroder N. 2011. Modulatory influence of dopamine receptors on consolidation of object recognition memory. Neurobiol Learn Mem 95: 305-310.

Duva CA, Floresco SB, Wunderlich GR, Lao TL, Pinel JP, Phillips AG. 1997. Disruption of spatial but not object-recognition memory by neurotoxic lesions of the dorsal hippocampus in rats. Behav Neurosci 111: 1184-1196.

Feenstra MG, Botterblom MH. 1996. Rapid sampling of extracellular dopamine in the rat prefrontal cortex during food consumption, handling and exposure to novelty. Brain Res 742: $17-24$. 
Galluzzi KE, Appelt DM, Balin BJ. 2010. Modern care for patients with Alzheimer disease: Rationale for early intervention. J Am Osteopath Assoc 110: S37-S42.

Girault JA, Greengard P. 2004. The neurobiology of dopamine signaling. Arch Neurol 61: 641-644.

Guzmán-Ramos K, Osorio-Gomez D, Moreno-Castilla P, BermudezRattoni F. 2010. Off-line concomitant release of dopamine and glutamate involvement in taste memory consolidation. J Neurochem 114: $226-236$

Himeno E, Ohyagi Y, Ma L, Nakamura N, Miyoshi K, Sakae N, Motomura K, Soejima N, Yamasaki R, Hashimoto T, et al. 2010. Apomorphine treatment in Alzheimer mice promoting amyloid- $\beta$ degradation. Ann Neurol 69: 248-256.

Jankowsky JL, Melnikova T, Fadale DJ, Xu GM, Slunt HH, Gonzales V, Younkin LH, Younkin SG, Borchelt DR, Savonenko AV. 2005. Environmental enrichment mitigates cognitive deficits in a mouse model of Alzheimer's disease. J Neurosci 25: 5217-5224.

Jay TM. 2003. Dopamine: A potential substrate for synaptic plasticity and memory mechanisms. Prog Neurobiol 69: 375-390.

Joyce JN, Kaeger C, Ryoo H, Goldsmith S. 1993. Dopamine D2 receptors in the hippocampus and amygdala in Alzheimer's disease. Neurosci Lett 154: $171-174$

Joyce JN, Myers AJ, Gurevich E. 1998. Dopamine D2 receptor bands in normal human temporal cortex are absent in Alzheimer's disease. Brain Res 784: 7-17.

Jurgensen S, Antonio LL, Mussi GE, Brito-Moreira J, Bomfim TR, De Felice FG, Garrido-Sanabria ER, Cavalheiro EA, Ferreira ST. 2010. Activation of D1/D5 dopamine receptors protects neurons from synapse dysfunction induced by amyloid- $\beta$ oligomers. J Biol Chem 286: $3270-3276$.

Kemppainen N, Laine M, Laakso MP, Kaasinen V, Nagren K, Vahlberg T, Kurki T, Rinne JO. 2003. Hippocampal dopamine D2 receptors correlate with memory functions in Alzheimer's disease. EurJNeurosci 18: 149-154

Kumar U, Patel SC. 2007. Immunohistochemical localization of dopamine receptor subtypes (D1R-D5R) in Alzheimer's disease brain. Brain res 1131: $187-196$.

LaFerla FM. 2010. Pathways linking A $\beta$ and tau pathologies. Biochem Soc Trans 38: 993-995.

LaFerla FM, Green KN, Oddo S. 2007. Intracellular amyloid- $\beta$ in Alzheimer's disease. Nat Rev Neurosci 8: 499-509.

Martorana A, Mori F, Esposito Z, Kusayanagi H, Monteleone F, Codeca C, Sancesario G, Bernardi G, Koch G. 2009. Dopamine modulates cholinergic cortical excitability in Alzheimer's disease patients. Neuropsychopharmacology 34: 2323-2328.

Mastrangelo MA, Bowers WJ. 2008. Detailed immunohistochemical characterization of temporal and spatial progression of Alzheimer's disease-related pathologies in male triple-transgenic mice. $B M C$ Neurosci 9: 81.

Nagai T, Takuma K, Kamei H, Ito Y, Nakamichi N, Ibi D, Nakanishi Y, Murai M, Mizoguchi H, Nabeshima T, et al. 2007. Dopamine D1 receptors regulate protein synthesis-dependent long-term recognition memory via extracellular signal-regulated kinase $1 / 2$ in the prefrontal cortex. Learn Mem 14: 117-125.

Nazarali AJ, Reynolds GP. 1992. Monoamine neurotransmitters and their metabolites in brain regions in Alzheimer's disease: A postmortem study. Cell Mol Neurobiol 12: 581-587.

Nicholson RM, Kusne Y, Nowak LA, LaFerla FM, Reiman EM, Valla J. 2010. Regional cerebral glucose uptake in the 3xTG model of Alzheimer's disease highlights common regional vulnerability across AD mouse models. Brain Res 1347: 179-185.

Oddo S, Caccamo A, Kitazawa M, Tseng BP, LaFerla FM. 2003a. Amyloid deposition precedes tangle formation in a triple transgenic model of Alzheimer's disease. Neurobiol Aging 24: 1063-1070.

Oddo S, Caccamo A, Shepherd JD, Murphy MP, Golde TE, Kayed R, Metherate R, Mattson MP, Akbari Y, LaFerla FM. 2003b.
Triple-transgenic model of Alzheimer's disease with plaques and tangles: Intracellular $\mathrm{A} \beta$ and synaptic dysfunction. Neuron 39: $409-421$.

Oddo S, Billings L, Kesslak JP, Cribbs DH, LaFerla FM. 2004. A $\beta$ immunotherapy leads to clearance of early, but not late, hyperphosphorylated tau aggregates via the proteasome. Neuron 43: 321-332.

Paxinos G, Franklin K. 2007. The mouse brain in stereotaxic coordinates. Elsevier Academic Press, Amsterdam.

Pietropaolo S, Feldon J, Yee BK. 2008. Age-dependent phenotypic characteristics of a triple transgenic mouse model of Alzheimer disease. Behav Neurosci 122: $733-747$.

Preda S, Govoni S, Lanni C, Racchi M, Mura E, Grilli M, Marchi M. 2008. Acute $\beta$-amyloid administration disrupts the cholinergic control of dopamine release in the nucleus accumbens. Neuropsychopharmacology 33: $1062-1070$.

Querfurth HW, LaFerla FM. 2010. Alzheimer's disease. N Engl J Med 362: 329-344.

Roozendaal B, Castello NA, Vedana G, Barsegyan A, McGaugh JL. 2008. Noradrenergic activation of the basolateral amygdala modulates consolidation of object recognition memory. Neurobiol Learn Mem 90: $576-579$.

Rossato JI, Bevilaqua LR, Izquierdo I, Medina JH, Cammarota M. 2009. Dopamine controls persistence of long-term memory storage. Science 325: $1017-1020$.

Rothblat LA, Kromer LF. 1991. Object recognition memory in the rat: The role of the hippocampus. Behav Brain Res 42: 25-32.

Rudbeck L, Dissing J. 1998. Rapid, simple alkaline extraction of human genomic DNA from whole blood, buccal epithelial cells, semen and forensic stains for PCR. BioTechniques 25: 588-592.

Sarter M, Bruno JP, Parikh V. 2007. Abnormal neurotransmitter release underlying behavioral and cognitive disorders: Toward concepts of dynamic and function-specific dysregulation. Neuropsychopharmacology 32: $1452-1461$.

Schultz W. 2007. Behavioral dopamine signals. Trends Neurosci 30: 203-210.

Selkoe DJ. 2001. Alzheimer's disease: Genes, proteins, and therapy. Physiol Rev 81: 741-766.

Shearman E, Rossi S, Szasz B, Juranyi Z, Fallon S, Pomara N, Sershen H, Lajtha A. 2006. Changes in cerebral neurotransmitters and metabolites induced by acute donepezil and memantine administrations: A microdialysis study. Brain Res Bull 69: 204-213.

Smith JA, Knight RG. 2002. Memory processing in Alzheimer's disease. Neuropsychologia 40: 666-682.

Storga D, Vrecko K, Birkmayer JG, Reibnegger G. 1996. Monoaminergic neurotransmitters, their precursors and metabolites in brains of Alzheimer patients. Neurosci Lett 203: 29-32.

Stupien G, Florian C, Roullet P. 2003. Involvement of the hippocampal CA3-region in acquisition and in memory consolidation of spatial but not in object information in mice. Neurobiol Learn Mem 80: $32-41$.

Ungless MA. 2004. Dopamine: The salient issue. Trends Neurosci 27: $702-706$.

Viggiano MP, Galli G, Righi S, Brancati C, Gori G, Cincotta M. 2008. Visual recognition memory in Alzheimer's disease: Repetition-lag effects. Exp Aging Res 34: 267-281.

Winblad B, Hardy J, Backman L, Nilsson LG. 1985. Memory function and brain biochemistry in normal aging and in senile dementia. Ann N Y Acad Sci 444: 255-268.

Zhu XO, McCabe BJ, Aggleton JP, Brown MW. 1997. Differential activation of the rat hippocampus and perirhinal cortex by novel visual stimuli and a novel environment. Neurosci Lett 229: 141-143.

Received February 24, 2012; accepted in revised form June 19, 2012. 


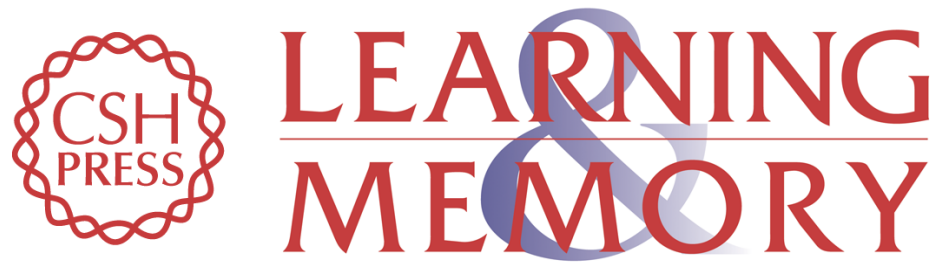

\section{Restoration of dopamine release deficits during object recognition memory acquisition attenuates cognitive impairment in a triple transgenic mice model of Alzheimer's disease}

Kioko Guzmán-Ramos, Perla Moreno-Castilla, Monica Castro-Cruz, et al.

Learn. Mem. 2012, 19:

Access the most recent version at doi:10.1101//m.026070.112

References This article cites 62 articles, 9 of which can be accessed free at:

http://learnmem.cshlp.org/content/19/10/453.full.html\#ref-list-1

License

Email Alerting

Service

Receive free email alerts when new articles cite this article - sign up in the box at the top right corner of the article or click here. 